\title{
ADOLESCÊNCIA, FAMÍLIA E ESCOLHAS: IMPLICAÇÕES NA ORIENTAÇÃO PROFISSIONAL
}

\author{
Maria Elisa Grijó Guahyba de Almeida* \\ Luis Ventura de Pinho**
}

\section{RESUMO}

A adolescência é uma fase do ciclo de vida na qual o indivíduo passa por transiçóes que acarretam grandes mudanças em seu desenvolvimento. Este é um período de consolidação da identidade, em que o jovem se depara com uma série de escolhas que definirão seu futuro, dentre elas a escolha profissional. A família é apontada como um dos principais elementos que podem tanto ajudar quanto dificultar o jovem em sua escolha no momento da decisão profissional. As influências familiares podem ser trabalhadas de diversas maneiras, durante o processo de orientação profissional, auxiliando o adolescente a compreender as questôes que estão por trás de sua escolha. Quando o jovem reconhece essas influências, ele pode utilizá-las, de forma consciente, ao estabelecer o seu projeto de vida pessoal e profissional.

Palavras-chave: adolescência; influências familiares; escolha profissional; orientação profissional.

\section{AbSTRACT}

ADOLESCENCE, FAMILY AND CHOICES: IMPLICATIONS ON CAREER GUIDANCE

Adolescence is a life-span stage in which the individual goes through transitions that can lead to big shifts in development. This is a moment of identity consolidation, when the adolescent faces many choices that will define his/her future, such as a career choice. Family is one of the major elements that can help or hinder this moment of professional decision. Family influences can be assessed by many ways during the career guidance process, in means of helping the

* Psicóloga; Orientadora profissional; Mestre em Ciências da Educação pela Universidade de Aveiro, Portugal.

** Professor Associado do Departamento de Ciências da Educação da Universidade de Aveiro, Portugal. 
adolescent understand the issues that are beneath this important choice. When the young person recognizes those influences, helshe can use them consciously to construct his/her personal and professional life project.

Keywords: adolescence; family influence; career choice; career guidance.

\section{INTRODUÇÃO}

Quando um adolescente se depara com a escolha de uma profissão, não estão apenas em jogo seus interesses e aptidões, mas também a maneira como ele vê o mundo, como ele próprio se vê, as informações que possui acerca das profissões, as influências externas advindas do meio social, dos pares e, principalmente, da família.

A questão da atuação da família na escolha profissional transparece tanto no discurso dos pais como no discurso dos próprios jovens. Há sempre alguma maneira de influenciar, seja expressando abertamente a opinião, muitas vezes pressionando o filho a seguir determinada profissão, seja de maneira mais sutil ou manipuladora.

Desde muito cedo o adolescente deve optar por uma profissão, uma escolha que lhe parece definitiva, já que deve ser "para o resto da vida". Isto, muitas vezes, sem nem mesmo ter formado sua identidade. Considerando uma abordagem psicossocial do desenvolvimento, na qual a identidade é formada também levando-se em conta o contexto no qual o indivíduo está inserido, a família possui papel fundamental nesta formação.

O indivíduo, ao nascer, já carrega consigo uma série de expectativas da família, que ele deverá (ou não) cumprir ao longo da vida Os pais depositam seus sonhos nos projetos que fazem para o futuro do filho e este desenvolve-se dentro desse contexto, muitas vezes ouvindo que deve seguir a profissão do pai e/ou do avô, ou ouvindo que determinada profissão não é apropriada para o seu sexo.

Freqüentemente, nos processos de orientação profissional essas questōes familiares não possuem espaço. Testes psicométricos são aplicados, a fim de medir os interesses e aptidões do jovem, de forma a fornecer uma resposta que solucione a problemática da escolha profissional. No entanto, essa solução pode não ser bem vista aos olhos da família, fazendo com que o jovem acabe optando por seguir os desejos familiares.

As influências familiares podem ser trabalhadas de diversas maneiras durante o processo de orientação profissional, fazendo o jovem dar-se conta das questôes que estão por trás de sua escolha. Quando o jovem reconhece essas influênci- 
as, ele pode utilizá-las, de forma consciente, ao estabelecer o seu projeto pessoal e profissional.

\section{AdOLESCÊNCIA E MOMENTO DE ESCOLHAS}

A adolescência é um estádio do ciclo de vida no qual o indivíduo passa por transições que acarretam grandes mudanças em sua vida (Santos, 2005). É nessa fase que o jovem se depara com uma série de escolhas que definirão o seu futuro, dentre elas a escolha profissional. Neste primeiro tópico abordaremos, brevemente, algumas questões acerca da adolescência e das implicações das escolhas nesta fase.

A problemática da adolescência foi estudada a fundo por Erikson (1972). De acordo com este autor, é neste período que se organiza a construção da identidade do eu, sendo esta a base do desenvolvimento do indivíduo.

Conforme analisa Pinheiro (2003), o pensamento de Erikson foi diretamente influenciado pela psicanálise, no entanto ele se distancia desta linha teórica ao discordar de que a personalidade se forma definitivamente na infância, defendendo que o desenvolvimento ocorre ao longo da vida (life-span). Portanto, Erikson inaugura a idéia de que o desenvolvimento humano é co-extensivo à vida e que ocorre dentro de contextos socioculturais, sendo resultado da interação entre a pessoa e o ambiente (Pinheiro, 2003; Sprinthall \& Collins, 2003).

É através dos estádios do life-span que emerge o sentido de identidade, conceito de extrema importância na teoria eriksoniana que, conforme Claes (1985), "faz referência a um processo em vias de elaboração, uma construção nunca acabada do eu" (Claes, 1985: 147).

A principal tarefa da adolescência é a resolução da crise da identidade (identidade x confusão da identidade). Erikson (1959, citado por Claes, 1985) afirma que na adolescência deve-se estabelecer uma ligação entre o passado - "o que eu era como criança" - e o futuro - "o que serei como adulto" -, podendo o adolescente assim projetar planos coerentes para a vida adulta. É o período de estabelecer um senso de identidade pessoal, assegurando, conforme Erikson, "o sentido de ser um consigo próprio, que cresce e se desenvolve" (Erikson, citado por Pinheiro, 2003: 16). Assim, o processo de crescimento saudável se dá através de uma resolução positiva da crise (Sprinthall \& Collins, 2003), permitindo a continuidade para o estádio seguinte.

Segundo Sampaio (1995), a identidade e a autonomia são as principais questôes da adolescência. Este autor considera a formação da identidade como um processo dinâmico, que resulta da assimilação e rejeição das identificações sofri- 
das ao longo da vida, assim como das interações entre o desenvolvimento pessoal e as influências sociais.

No entanto, o processo de constituição da identidade do indivíduo se torna ainda mais complexo diante da multiplicidade de opçôes que a sociedade contemporânea oferece e da sua constante transformação. Assim,

o adolescente em permanente reconstrução interna deve acompanhar essas mudanças e precisa se posicionar diante delas. Entretanto, observamos que os mesmos vêm sendo "bombardeados" por informaçōes que nem sempre contribuem para a constituição de uma identidade genuína (Lemos, 2001: 29).

A construção da identidade ocupacional está, como afirma Lisboa (1997), diretamente vinculada à identidade pessoal, pois ambas incluem todas as identificaçôes feitas pelo indivíduo ao longo da vida. De acordo com Conger e Petersen (1984), a identidade ocupacional forma uma parte importante do senso de identidade, constituindo-se numa das principais tarefas desenvolvimentais da adolescência.

Sendo assim, a identidade ocupacional forma-se através da autopercepção que o indivíduo tem dos papéis profissionais com os quais tem contato ao longo de sua existência, principalmente no que diz respeito a figuras significativas, como pais, familiares e professores (Lisboa, 1997). A escolha é, portanto, parte da definição desta identidade ocupacional (Santos, 2005).

De acordo com Bohoslavsky (1998), a identidade ocupacional não é vista como algo definido, mas sim "como um momento de um processo submetido às mesmas leis e dificuldades daquele que conduz à conquista da identidade pessoal" (Bohoslavsky, 1998: 30). Apesar de a identidade ocupacional se desenvolver como um aspecto da identidade pessoal, pode-se assim dizer que são dois processos que caminham juntos em determinado momento de transição - a adolescência - da vida do indivíduo.

É neste contexto de resolução de crise e formação da identidade que o adolescente se depara com a necessidade de implementar uma série de escolhas relativas ao seu futuro escolar e profissional. $\mathrm{O}$ conceito de crise adquire aqui um sentido amplo, que em chinês denota, em seus caracteres, o sentido de "perigo" (ou risco) e "oportunidade" (Levinson, 1990), ou ainda, segundo Bohoslavsky (1998) "a idéia de passagem, de reajustamento, de nova forma de adaptação" (Bohoslavsky, 1998: 36).

De acordo com outros autores, "a escolha acompanha o homem em toda sua vivência emocional” (Pinto, 2003: 82) e qualquer escolha implica perda, o aban- 
dono de investimentos e o seu luto (Pinto, 2003), implica em deixar para trás outras opçōes (Santos, 2005).

Quando se trata da escolha profissional, o adolescente deve optar não só por um curso ou por uma atividade de trabalho, mas também por um estilo de vida, uma rotina, o ambiente do qual fará parte. Enfim, decide não só o que quer fazer, mas também o que quer ser (Filomeno, 1997).

A dimensão temporal da escolha faz-se importante, pois o momento da escolha é o momento presente e, como afirma Soares (2002), é nesse presente que o adolescente definirá um futuro, por sua vez baseado em suas referências passadas.

Diante de tantas implicações da escolha profissional, esta fase pressupõe o surgimento de conflitos, ansiedade, além da elaboração de lutos, pois "escolher é algo que implica em renunciar a certas coisas" (Filomeno, 1997: 33).

Os lutos a serem elaborados são, segundo Levenfus (1997), os lutos básicos da adolescência que emergem face à escolha profissional. De acordo com esta autora, os seguintes lutos advêm das perdas por escolhas na adolescência: o luto pela perda dos pais da infância, pela perda das escolhas profissionais realizadas, pelo corpo adolescente, pelas identificaçôes profissionais que abandona, pelo papel e pela identidade adolescente.

Este é um momento de confronto entre as fantasias e identificações da infância e as exigências reais, seja de uma profissão, seja do mundo adulto. Sendo assim, o adolescente que escolhe encontra-se numa fase de transição, de mudanças, de adaptação e de ajustamento, quando deixa para trás o mundo infantil para entrar na vida adulta.

Por sua vez, os pais deixam de ser os ídolos admirados da infância e devem também elaborar o luto pela desidealização por parte dos filhos:

Freqüentemente os pais não entendem a complexidade do conflito que surge como conseqüência de terem sido desidealizados pelos filhos adolescentes, conflito que faz parte da mudança importante que experimentam face às ideologias, aos sistemas de valores e às novas perspectivas com que o mundo é contemplado (Grimberg \& Grimberg, 1998: 72).

\section{As INFLUÊNCIAS DA FAMÍlIA NA ESCOLHA PROFISSIONAL}

São muitos os fatores que influem na escolha de uma profissão, desde características pessoais a convicções políticas e religiosas, valores, crenças, contexto socioeconômico, família e pares. Segundo Santos (2005), a família é apontada pela 
literatura como um dos principais aspectos que podem tanto ajudar quanto dificultar o jovem no momento da decisão profissional.

Quando a pessoa nasce, ela já vem encarregada de ocupar determinado lugar, além de ser depositária de diversas expectativas, desejos e fantasias dos pais e de toda a família (Krom, 2000). O indivíduo cresce com essa carga de expectativas que irá, de alguma maneira, refletir em seu desenvolvimento vocacional e no momento da escolha por uma profissão (Soares, 2002). Acaba, então, por ser inevitável que o adolescente busque fazer uma escolha profissional de acordo com os valores de sua família.

Inúmeros são os teóricos - de diferentes países - que têm estudado a influência da família no processo de escolha profissional, bem como outras variáveis contextuais que também influenciam este processo. $\mathrm{Na}$ literatura brasileira encontram-se estudos, em crescimento, acerca da influência da família, mais especificamente no que diz respeito ao momento de escolha profissional do jovem.

Como exemplo, citamos o estudo de Santos (2005) que teve como objetivo verificar as percepçōes dos adolescentes quanto à influência da família e dos pares na escolha profissional. Através da análise do discurso de 16 jovens entrevistados, foram levantados indicadores da importância e da influência dos pais no processo de tomada de decisão.

Esta pesquisa mostrou que o jovem tende a buscar o primeiro apoio na família na hora em que precisa escolher uma profissão, como também afirma Gavilán (2006). É na família que o jovem encontra o suporte para a realização do seu projeto. Conforme percebido por Santos (2005), “a família é um entre os vários facilitadores ou dificultadores do processo de escolha, mas antes de tudo tem um papel importante na realidade do adolescente e deve ser levada em consideração quando se trata de projeto de vida" (Santos, 2005: 63).

A autora conclui que a família tem influência sobre o projeto do adolescente, sendo a "opinião dos pais" e o "sentimento gerado pela opinião dos pais" indicadores desta influência.

De acordo com Soares $(1997,2002)$, os pais constroem projetos para o futuro do filho e desejam que ele corresponda à imagem sobre ele projetada, propondo, muitas vezes, objetivos que na realidade eram sonhos seus que não puderam realizar na juventude. O filho se torna, então, um depositário das aspiraçôes dos pais, absorvendo a responsabilidade de escolher a profissão que o pai não pôde seguir (Andrade, 1997). De alguma maneira, os pais introduzem em seus discursos seus próprios desejos sobre os projetos de seus filhos, sem nem mesmo daremse conta (Pinto \& Soares, 2004). 
A profissão dos pais e familiares e a forma como estes vivenciam suas ocupações também é fator influente na decisão do jovem. Segundo Filomeno (1997), o filho estabelece conceitos e valores acerca das profissões de acordo com o que é falado pela família.

Silva (2006), analisando os relatos de adolescentes entre 14 e 17 anos, do sexo masculino, os quais entrevistou em sua pesquisa, constata que as identificações com as profissões e com profissionais se dão por meio das relações que o jovem estabelece com o mundo adulto. Daí a importância dessas identificaçôes com os pais e com outros membros da família com os quais o jovem interage.

Os filhos nem sempre reconhecem as influências familiares, pois muitas vezes elas estão implícitas, tanto na ideologia familiar (Andrade, 1997) sobre os valores e conceitos ocupacionais, como nos mitos ou legados familiares. Assim, ao optar por uma profissão o jovem "pode estar seguindo, confrontando ou transformando um mito familiar" (Filomeno, 1997: 69).

Stierlin (citado por Groisman, Lobo \& Cavour, 1996) foi quem desenvolveu o conceito de legado: "o elemento nuclear do legado é o vínculo de lealdade que une o delegante com o delegado" (Stierlin, citado por Groisman, Lobo \& Cavour, 1996: 30). Isto significa que os pais esperam lealdade dos filhos, lealdade essa que vai sendo cobrada de geração em geração.

Salomão (2003) define lealdade na família como: "corresponder às regras de união e aos demais mitos da família” (Salomão, 2003: 260). Conforme Groisman, Lobo e Cavour (1996), as lealdades criam uma rede de obrigaçôes no sistema familiar na qual cada membro da família vai sentir-se subordinado às expectativas que deverá cumprir.

Segundo Krom (2000), os fatores que se mostram mais importantes nas lealdades são os vínculos psicológicos. Quando algum membro da família não corresponde a essas expectativas de lealdades, pode haver uma sobrecarga nos laços familiares, bem como um enfraquecimento dos sentidos organizadores que as lealdades atribuem à vida.

A mesma autora nos diz que os períodos transacionais, como a adolescência e o momento de escolha profissional, são importantes, pois facilitam a passagem dos conteúdos intergeracionais, principalmente aqueles determinados pelas lealdades familiares. A escolha das profissōes e ocupaçōes na família, muitas vezes, obedece a essas lealdades.

Através do estudo dos mitos familiares, Krom (2000) pôde concluir que estes são os conteúdos mais abrangentes na família, que pode organizá-los e direcioná-los ao longo do tempo. Para a autora, "o mito constitui em sua essência 
a concepção de mundo própria da família, onde se cria a realidade familiar e o mapa do mundo individual" (Krom, citado por Krom, 2000: 32).

De acordo com Filomeno (1997), o adolescente pode estar seguindo, confrontando ou, até mesmo, transformando o mito familiar. No entanto, seguir o mito nem sempre é sinal de sucesso profissional, assim como a sua confrontação não significa o fracasso.

As formas de influenciar podem também ser explícitas, através de opiniões expressas pelos membros familiares. $\mathrm{O}$ fato é que na estrutura familiar por vezes o jovem sente-se forçado a seguir carreiras familiares pela pressão imposta na família. Por outro lado, conforme constatou Santos (2005), a liberdade excessiva por parte dos pais pode causar insegurança e, até mesmo, uma sensação de desamparo e dúvidas.

Faz-se importante, então, que o jovem considere as influências recebidas pela família, quer elas sejam explícitas, quer sejam sutis e expressas implicitamente. Segundo Andrade (1997), o reconhecimento destas influências pode vir a colaborar com a elaboração de um projeto de carreira, pois o indivíduo pode usá-las de forma positiva e construtiva, de maneira a adequá-las aos seus próprios desejos e valores.

\section{IMPLICAÇÕES NO PROCESSO DE ORIENTAÇÃO PROFISSIONAL}

De acordo com Müller (1988), "chegar a uma escolha vocacional supõe um processo de tomada de consciência de si mesmo e a possibilidade de fazer um projeto que significa imaginar-se antecipadamente cumprindo um papel social e ocupacional” (Müller, 1988: 141).

Neste sentido, a orientação profissional pode auxiliar o adolescente a realizar uma escolha mais esclarecida se reconhecer as influências que sofre, que estão relacionadas ao ambiente em que ele se desenvolveu: a família, a escola, o meio social e econômico, a religiāo e mesmo as questóes psicológicas. Ou seja, a intervenção em orientação profissional deve proporcionar ao jovem orientando um momento de reflexão, especialmente acerca do que está por trás da sua escolha.

Para tal, considera-se necessário um processo de orientação profissional mais aprofundado, que possa abordar as questões relativas às influências familiares. A abordagem construtivista, com uma visão de mundo contextualizada e holística, tem por objetivo incentivar o orientando a refletir ativamente e atribuir significado à sua história de vida e ao seu desenvolvimento vocacional.

Segundo as concepções construtivistas, o indivíduo constrói suas significações pessoais que são refletidas nas experiências passadas e presentes, bem como 
na variedade de papéis vivenciados ao longo da vida (Neimeyer \& Neimeyer, 1993; Brott, 2005).

Quando se adota uma visão holística, a questão da escolha profissional não pode ser considerada como uma parte a ser solucionada, mas sim como um elemento de um todo que é o indivíduo. Sendo assim, não se pode ignorar as influências da cultura, da família, da religião e da escola no processo de orientação vocacional. Todos estes aspectos fazem parte da identidade do orientando (Santos e cols., 2001).

Trabalhar através das narrativas e significações da história de vida do indivíduo faz com que ele se envolva no processo de maneira ativa, uma vez que o foco está em suas experiências subjetivas e no contexto em que ele está inserido (Patton \& McMahon, 2006).

Partindo dos pressupostos construtivistas em orientação profissional, algumas técnicas podem ser utilizadas para trabalhar as influências da família nas escolhas. Uma dessas técnicas é o genograma, que tem por objetivo explorar as influências (explícitas ou implícitas) da família no projeto de vida e na escolha profissional do indivíduo (Müller, 1988).

Consiste na elaboração de uma árvore genealógica na qual se incluem as ocupações e/ou profissões de cada membro da família, ou de pessoas que, de algum modo, possam influenciar - ou ter influenciado - suas atitudes, aspirações (Leitão, 2004) e supostas escolhas. Conforme Levenfus (1997), o orientador tem a possibilidade de explorar, junto ao orientando, não só as influências familiares, mas também sociais, culturais e ideológicas que se colocam na construção de um projeto pessoal e profissional do adolescente.

Outras técnicas também são utilizadas com os adolescentes, como a História do nome próprio, a História profissional da família, a História da vida trigeracional (Filomeno, 1997) e o desenho da família com estórias (Trinca, citado por Lemos, 2001).

O trabalho com os pais/família também é imprescindível. $\mathrm{O}$ processo da escolha por uma profissão e da entrada no mundo adulto gera ansiedades e conflitos não só nos adolescentes, mas também nos pais, que possuem uma série de expectativas em relação ao futuro de seus filhos.

Uma proposta de trabalho com os pais/familiares pode ser a realização de reunióes de grupo, visando obter uma compreensão de seu papel diante da situação de escolha que seus filhos enfrentam, refletindo e reconhecendo a influência que exercem sobre estas escolhas e a importância de uma escolha consciente e ajustada (Bohoslavsky, 1998). Ou, ainda, podem ser organizados grupos de reflexão e discussão que permitam situá-los a respeito da fase da adolescência, dos 
problemas, dificuldades, ansiedades e expectativas que despertam em seus filhos neste momento. $\mathrm{O}$ importante é fazer com que os pais/familiares possam refletir acerca do momento do adolescente, bem como amenizar as ansiedades geradas em torno das escolhas dos filhos.

De acordo com o trabalho implementado por Gonçalves (1997), alguns temas podem ser abordados através de dinâmicas de grupo com os pais/familiares: refletir com os pais sobre a postura diante de suas escolhas e as escolhas de seus filhos, trabalhar a questão da dificuldade no relacionamento com os adolescentes e a insegurança de pais e filhos em momentos de separação.

Ao fim deste trabalho, a autora pôde notar que os adolescentes cujos pais participaram dos encontros se mostraram mais calmos, seguros e menos ansiosos frente às suas escolhas. Já os pais relataram que as dinâmicas de grupo lhes proporcionaram um maior crescimento individual, pois seus conflitos, dúvidas, inseguranças e ansiedades puderam ser divididos com o grupo, através de uma reflexão coletiva.

A influência da família, ou da rede de relações que se forma em cada família, está, segundo Soares (2002), sempre presente de alguma maneira nas diferentes escolhas que se fazem na vida. Daí a importância de o adolescente reconhecer estas influências, para que possa elaborar uma escolha consciente, responsável e assertiva.

\section{REFERÊNCIAS BIBLIOGRÁFICAS}

Andrade, T. D. (1997). A família e a estruturação ocupacional do indivíduo. Em Levenfus, R. S. Psicodinâmica da escolha profissional (pp. 123-134). Porto Alegre: ArtMed.

Bohoslavsky, R. (1998). Orientação vocacional: a estratégia clínica. São Paulo: Martins Fontes. Brott, P. (2005). A constructivist look at life roles. Career Development Quarterly, 54, 2, $138-150$.

Claes, M. (1985). Os problemas da adolescência. Lisboa: Editorial Verbo.

Conger, J. J. \& Petersen, A. C. (1984). Adolescence and youth: psychological development in a changing world. New York: Harper \& Row.

Erikson, E. (1972). Adolescence et crise. Paris: Flammarion.

Filomeno, K. (1997). Mitos familiares e escolha profissional: uma visão sistêmica. São Paulo: Vetor.

Gavilán, M. (2006). La transformación de la orientación vocacional hacia un nuevo paradigma. Rosario: HomoSapiens. 
Gonçalves, G. Z. (1997). Os filhos, os pais e a escolha profissional. Anais do III Simpósio Brasileiro de Orientação Vocacional/Ocupacional (pp. 195-204). ULBRA, Canoas.

Grimberg, L. \& Grimberg, R. (1998). Identidade e mudança. Lisboa: Climepsi.

Groisman, M.; Lobo, M. \& Cavour, R. (1996). Histórias dramáticas: terapia breve para famílias e terapeutas. Rio de Janeiro: Rosa dos Ventos.

Krom, M. (2000). Família e mitos, prevenção e terapia: resgatando histórias. São Paulo: Summus.

Leitão, L. M. (2004). Metodologias de avaliação qualitativa em aconselhamento vocacional. Psychologica, Extra-série (número de homenagem ao Prof. Doutor Manuel Viegas de Abreu), 249-262.

Lemos, C. G. (2001). Adolescência e escolha da profissão. São Paulo: Vetor.

Levenfus, R. S. (1997). Os lutos da escolha profissional. Em Levenfus, R. S. Psicodinâmica da escolha profissional (pp. 109-122). Porto Alegre: ArtMed.

Levinson, D. J. (1990). A theory of life structure development in adulthood. Em Alexander, C. N. \& Langer, E. J. (eds.). Higher stages of human development (pp. 35-53). New York: Oxford University Press.

Lisboa, M. D. (1997). Ser quando crescer... A formação da identidade ocupacional. Em Levenfus, R. S. Psicodinâmica da escolha profissional (pp. 109-122). Porto Alegre: ArtMed. Müller, M. (1988). Orientação vocacional: contribuiçôes clinicas e educacionais. Porto Alegre: Artes Médicas.

Neimeyer, G. J. \& Neimeyer, R. A. (1993). Defining the boundaries of constructivist assessment. Em Neimeyer, G. J. (Ed.). Constructivist assessment-a casebook (pp. 1-30). Newbury Park, CA: SAGE.

Patton, W. \& McMahon, M. (2006). Constructivism: what does it mean for career counselling? Em McMahon, M. \& Patton, W. Career counselling, constructivist approaches (pp. 3-15), London: Routledge.

Pinheiro, M. R. M. (2003). Uma época especial: suporte social e vivências académicas na transição e adaptação ao ensino superior. Tese de Doutoramento. Faculdade de Psicologia e Ciências da Educação, Universidade de Coimbra.

Pinto, H. R. \& Soares, M. C. (2004). Approches de l'influence des parents sur le développement vocationnel des adolescents. L'orientation scolaire et professionnelle, 33, 1, 7-24.

Pinto, J. M. (2003). Adolescência e escolhas. Coimbra: Quarteto.

Salomão, S. (2003). Perdas, situações inacabadas e reconstruções: uma contribuição da terapia familiar sistêmica a Gestalt-terapia. Em Groisman, M. (Org.). Além do paraíso: perdas e transformaçôes na familia. Rio de Janeiro: Núcleo-Pesquisas.

Sampaio, D. (1995). Inventem-se novos pais. Lisboa: Caminho. 
Santos, E. J. R.; Ferreira, J. A.; Blustein, D. L.; Fama, L.; Finkelberg, S.; Ketterson, T.; Shaeffer, B.; Schwam, M. \& Skau, M. (2001). A construção de convergências nos sistemas de aconselhamento vocacional e de carreira. Psychologica, 26, 161-174.

Santos, L. M. M. (2005). O papel da família e dos pares na escolha profissional. Psicologia em Estudo, 10, 1, 57-66.

Silva, J. J. (2006). O papel da familia na escolha profissional. São Caetano do Sul: Yendis. Soares, D. H. P. (1997). Uma abordagem genealógica a partir do Genoprofissiograma e do Teste dos Três Personagens. Em Levenfus, R. S. Psicodinâmica da escolha profissional (pp. 135-170). Porto Alegre: ArtMed.

- (2002). A escolha profissional: do jovem ao adulto. São Paulo: Summus.

Sprinthall, N. A. \& Collins, A. W. (2003). Psicologia do adolescente. Lisboa: Fundação Calouste Gulbenkian.

Recebido em 28 de novembro de 2007 Aceito para publicação em 06 de junho de 2008 